\title{
TERMS IN COMPASS WORK
}

SIR,-Reading the review by J. E. D. Williams of Air Navigation, Theory and Practice (this Journal, Vol. VI, p. I 04), I am prompted to make an appeal that the Institute, if not navigators in general, should use standardized and correct technical terms.

Compasses in general use today can be divided into three main types, if we omit sun and sky compasses \&c. These are:

Magnetic Compasses which depend on the magnetic field of the Earth for their directional property.

Gyro-Compasses which depend on the rotation of the Earth and the force of gravity.

Gyro-Magnetic Compasses which depend on the magnetic field of the Earth for their directional property, but use a gyroscope to stabilize some part of the system.

Magnetic compasses may be of either the pivoted needle or of the inductor type. Both types are used as the directional element in gyro-magnetic compasses.

Mr. Williams makes two statements which, though he knows what he means and so do we, are actually nonsense. He says 'with gyrosyn compasses, the magnetic compass is merely a last-resort device'; but the primary directional element of the gyrosyn compass is a magnetic compass and without it the instrument does not function. How can the magnetic compass be a last-resort device? Presumably he is referring to the emergency magnetic compass, but he does not say so.

A little later he says 'one widely used type of gyro-compass is not even fitted with $B$ and $C$ correctors'. I can assure him that no gyro-compass is now fitted with $B$ and $C$ correctors. It does not need them since it is unaffected by local magnetic fields (unless we are involved with exceptionally strong magnetic fields as were found in the early mine destructor ships). What he is of course referring to is a gyro-magnetic compass; but why not call it by its right name?

It may seem an anachronism that such a modern form of transport as the aeroplane should have to rely on something invented so long ago as the compass, but it is none the less a fact that gyro-compasses of present-day design cannot be used in the air. Because magnetic compasses are old is no excuse for calling them by the name of a more modern instrument, even though that instrument cannot be used in aircraft and so there can be no confusion among those who understand compasses. And where is this to end? Perhaps, since the Americans have now transferred the old nautical name of clipper to their aircraft we should return the compliment and call the 'Queens' stratocruisers, on the score that these monster liners are too modern to be called by the ancient name of ship. This should give no more grounds for confusion!

On the use of the expression 'compass swinging' I will not enlarge, except to point out that it is the aircraft which is swung, not the compass, and to admit that at one time the Admiralty was guilty of the same solecism.

National Maritime Museum,

Greenwich, S.E. xo.
Yours faithfully,

W. E. MaY 